\title{
Support and Control: The Biaxial Relationship between Government and Social Organizations
}

\author{
Yijun $\mathrm{Hu}^{1}$ \\ ${ }^{1}$ School of Political Science and Public Administration, China University of Political Science and Law, Beijing, \\ China \\ Correspondence: Yijun Hu, PhD Student, School of Political Science and Public Administration, China \\ University of Political Science and Law, Beijing 10088, China. E-mail: yijunhu@126.com
}

Received: July 10, 2017

doi:10.5539/ass.v13n9p151
Accepted: July 24, $2017 \quad$ Online Published: August 25, 2017

URL: https://doi.org/10.5539/ass.v13n9p151

\begin{abstract}
In an era with rapidly developing social organizations, the policies and strategies made by the government and its role in social organizations have been the focus of research. Indeed, extraneous civil society theory and corporatism theory have certain explanatory power. However, these two theories do not quite conform to the national situation of China. Based on this background, this paper is conducted with a focus on administration of social organizations by the government. With an analysis of both theory and current status, this paper breaks through the traditional uniaxial relationship and puts forward that the relationship between the government and social organizations is actually biaxial. That is to say, the effect of the government is indispensable and its two roles of support and control on social organizations are separated. On this basis, we further expound the model of support and control in the biaxial relationship.
\end{abstract}

Keywords: biaxial relationship, support and control, classified administration

\section{Proposal of the Issue}

\subsection{Research Background}

In an era with rapidly developing social organizations, the policies and strategies made by the government and its role in social organizations have been the focus of research. Research of this kind does not only enrich explorations of a country in social relations in terms of theory, but also helps to clarify roles of the government played in development of social organizations.

Both the traditional civil society theory and corporatism theory expound the relationship between a nation and its society, which has, to some extent, explained the mode of action by the government in social organizations. Nevertheless, it can be found by comparing these two kinds of theories that they both place the nation and social relationship on the same straight line. The only difference between the two theories originates from the difference in power comparison of the nation and its society. By contrast, this kind of uniaxial nation and social relationship theory is specifically manifested as generally classifying the mode of action by the government in social organizations to an integral whole. That is, the government plays a unified role simultaneously in all social organizations.

Under the guidance of the aforementioned nation and social relationship theory, two extreme situations will finally come up. One situation is that the government does not intervene in affairs of social organizations, allowing for their birth and development freely, and reflect their interests in public policies. The other situation is that the government completely controls social organizations and attain its purpose of managing the society by the means of social organizations. However, the actual situation in China is neither the case. Social organizations in China differ from social organizations in other countries which own rich social capital. The former have grown up and developed in the historical atmosphere of upholding the great unification and under the main background of emphasizing separation of government administration from commune management, separation of public service units from government, separation of associations from government and building a public government. Therefore, although they are the outcome of separation of the nation from the society, they also expect to be connected with the authority of the nation. Governmental administration on social organizations has transferred from strict control at the initial stage to the strategy of diversified development of fostering and 
absorbing, etc. All kinds of support have increased, such as, resource support and project support. Thus, it can be seen that, in the current national system, national and social relationship and the relationship between the government and social organizations are not purely competitive. Instead, the functions of the government on social organizations are especially prominent. This is unexplainable from the perspectives of civil society theory and corporatism theory. Then, what is the relationship between the government and social organizations in China? From the perspective of government functions, this issue can be further concretized as whether government functions are necessary, and, if they are necessary, then what is the mode of action by the government?

\subsection{Review of Literature}

As for the relationship between a nation and its social organizations, several representative viewpoints are proposed in the field of research on social organizations through studies for several decades. Kramer et al. come up with dualism and holism. According to them, different ideologies, historical and structural developments might generate two different types of relational schemas, namely, dualism or holism. In dualism, the government and social organizations are mutually competitive. Different from the government, social organizations are market-oriented to supply non-institutionalized social welfare. By contrast, the relational schema in holism is cooperative. The government provides plans and guidance for social organizations and supplies institutionalized social welfare by the means of social organizations.

Kuhnle and Selle classify the relations between nation and social organizations into four types according to the two indicators of "communication and intercourse" and "finance and control", which are integrated dependence, integrated independence, separated dependence and separate independence. The indicator of communication and intercourse focuses on the degree of scale, frequency and smooth of intercourse between social organizations and the government. The relationship between the two may be depicted as "closeness" or "alienation" based the differences of degree. The indicator of "finance and control" is used to express the degree of dependence of social organizations on finance provided by the government and also the degree of control by the government. Furthermore, it reveals whether social organizations are independent of the government.

According to the Resource Dependence Theory by Saidel et al., no organization is self-sufficient and if an organization wants to survive, it has to obtain resources from the outside environment. In the process of exchange with the outside world, the organization gradually becomes dependent on the environment. Yet, the degree of the dependence is determined by the following three factors: importance of resources, the degree of control and usage of resources by other specific groups and the degree of replaceability of resources.

The value of the theories aforementioned is tremendous and, indeed, can also bring beneficial enlightenment and reflections. However, there also exist some problems with these theories. The first theoretical model has broken through the traditional and inevitable theory of conflict between the society and the government, but this model is oversimplified. As a matter of fact, not only cooperation, but also competition exists between the government and social organizations. Competition is encompassed in cooperation. The second theoretical model provides such enlightenment to this research that the two functions of support and control have been separated. This separation indicates that the degree of control over social organizations by the government has no correlation with the kinship relationship between the two. Yet, the problem with this theory is that it is slightly prejudiced to state that means of control are merely manifested by financial regulations. The third relational schema has changed the research perspective and analyzes, from the perspective of resources, the possibility that social organizations immoderately depends on the government. Nevertheless, this way of analysis may inevitably ignore other means of control by the government. Besides, resource motivation and restraint are regarded as the same standard. This is likely to link together the changes of the two indicators.

\subsection{Research Methodology}

This paper attempts to summarize the model of biaxial relationship between the government and social organizations and explain different types of management means. The specific methods used in this paper are the method of text analysis and the method of comparative study. In text analysis, as this paper studies behaviors of the government, it is required to study and compare previous laws and regulations and policy changes of the government so as to broaden the research field of vision, guarantee the scientificity of the research results and get the most innovative research outcome. In comparative study, this paper aims to build the biaxial model of support and control, which naturally requires combination of different modes of actions. Therefore, when elaborating the four types of management methods of the government, this paper uses the method of comparative study to show the different functions of the government. 


\section{Theoretical Foundation: Dual Functions and Dual Attributes}

Generally speaking, a nation has dual functions, namely, suppressing function and the function of providing public services. On one hand, the government needs to provide all types of public services to meet the demands of the popular on living and development. On the other hand, the government has to respond to all kinds of challenges with all its strength and adopt different measures to suppress those behaviors which pose threat to social stability. No government is able to guarantee social stability and maintain its own governance without fulfilling neither of these two functions.

The dual attributes of a social organization are to provide public services and cohere the popular. A social organization has the ability to mobilize social power and help the government by means of providing public services and materials to meet the demands of the society. Demand of the government on this function of social organizations is mainly manifested in two aspects. On one hand, it is the demand to mobilize and integrate social resources. On the other hand, it is the need of the government to transfer its functions. In the meantime, the attribute of social organizations in cohering the popular poses challenges to governance of the government. First of all, social organizations' function in itself may launch some collective activities for interests of the members their represent, which might well challenge the authority of the government. Secondly, development of social organizations may occupy some traditional space of the government in the society and may accumulate considerable social power. Finally, to a certain extent, the fact that social organizations execute the function of services on behalf of the government sways the position of the government in the society. This gives rise to losses of government's social resources.

Under such circumstance, the role of the government is two-sided. The government might allow and even encourage existence of social organizations for the purpose of utilizing their function in providing public services to satisfy demands of the society. This is because the more the government satisfies demands of the society, the more possible it is to acquire the society's recognition of the government in its service capacity. However, at the same time, the government is also seeking for control over social organizations. The so-called control does not mean that the government imposes total restrictions on social organizations. Instead, it is to bring development of social organizations within the controllable scope of the government and to emphasize political leadership and guidance of the government on social organizations. In a manner of speaking, the government has affirmed existence and development of social organizations as a social power. Furthermore, within a controllable scope, the government begins to seek for coordination and cooperation to meet demands of the society and to consolidate its own position and expand its social power.

The function of support from the government mainly refers to resource support on social organizations, including financial resources and location resources, etc. By contrast, its function of control refers to control and administration of social organizations' behaviors. Obviously, these two functions neither correlate nor have the co-movement relation. That is to say, when the government provides referential policy or capital and location resources, this is not necessarily accompanied by its intensified control.

\section{Background of Reality: Control and Dependence}

Usually, development of social organizations has two routes. One is social promoting from bottom to top and the other is government guidance from top to bottom. In China, the government is not only indispensable in the process of birth and growth of social organizations, but, more importantly, plays a leading role. The most intuitive reason is that the government furnishes a relatively stable institutional environment and all kinds of policy supports for development of social organizations. Without legal protection provided by the government, social organizations might be caught in a disorderly and chaotic situation in the process of development, and even their legality might not be guaranteed.

Meanwhile, in China, indispensability of functions of the government, to a large extent, is affected by its historical development, and, within a short period of time, may not be altered essentially. In addition, when the society plays a leading role in social organizations, it tends to encounter relatively obvious limitations. These two facts are more profound evidence for necessity of government's functions.

\subsection{Control by the Government}

In the traditional social period of China, namely, before the founding of the People's Republic of China, the relationship between the nation and the society had always been governing and being governed and administration and being administered. The society never had the capacity in checking and balancing the nation. As the old saying goes, "All the lands and people belong to the emperor; all officials all over the country belong to the emperor". Hence, it can be found that the authority of the nation penetrated in all aspects of the society, 
without any boundary. The system of units in urban cities and the system of people commune in rural areas that were established at the beginning of the founding of PRC implied a deep "totalitarianism" feature. In such a totalitarianism country, the nation was the unique legal organization who monopolized all resources, whereas other organizations or groups had to be admitted by the systems of the nation if they intended to acquire legality and resources. Therefore, as a result of constraints in legality, autonomy and resources, there was no social organization in its true sense. It is only after the reform and opening up after the orientation of totalitarianism began to wear off. Transformation of government functions released a huge amount of social resources that had been monopolized by the government. Nonetheless, this process was long-drawn either in rural cities or in rural areas. Out of consideration of such elements as stability, the economic reform and political restricting have complied with two different types of logics. Hence, the marketization progress in the economic field and the autonomy progress in the social field can't be mentioned in the same breath. At the same time, development of social organizations which represent economic interests, social interests and public spirit suffers from collision of these two types of logics and is trapped in an intricate circumstance. The specific conflicts are manifested in two aspects. "Breakthrough" economic reform constantly pushes social organizations to acquire autonomy to fulfill the interests of the members they represent; "corrective" political restricting is concerned about gathering of social power collected by social organizations and, thus, takes restrictive measures. Thus, it is obvious that it is quite an endless process for social organizations' self-directed development under the conflicts and collision of these two types of logics.

A general view of the entire history in China tells us that the great unification has always been a political pursuit of the country. "Unification is normal, while division is abnormal". ((Huang, R., 1992, p.6) Even nowadays when functions of the government have been transformed, the nation is still far from thoroughly breaking away from its original way of thinking and route. Just as aforementioned, this is a slow process. However, this slow transformation also has certain practical rationality. The tradition of "great unification" has not only infinitely expanded the authority and capacity of the government, but also has caused psychological dependence of the popular. It has restrained social development both subjectively and objectively. Leadership of the government in social organizations is a realistic option under all the various restrictive frameworks.

\subsection{Dependence of Social Organizations}

The autocratic system with a long history of several thousand years has given rise to tractability of the common people and their national psychology to be easily satisfied with their plight. Furthermore, the system of units before the reform and opening up also gave rise to an individual's high dependence upon the units. A closed space in the units firmly controlled an individual's life and personal development. Marriage registration was unsuccessful without certification of the units, salary, medical security and housing were offered by the units and even political promotion, such as, admission to the Party and rise as a cadre, needed help from the units. All resources circulate within the closed space of units. If an employee resigned from his unit, he would had great difficulty in obtaining resources for survival and development. Besides, monopoly of the units on resources enabled them to have enough ability to furnish abundant welfare for individuals. The public goods furnished by the units also embraced all aspects in birth, senility, illness and death, as a result of which employees of the units were reluctant to take the initiative to resign from the units. In the meantime, the units might organize some activities. In a manner of speaking, units almost embraced all spheres of activities. As a result, the members of the units had no motivation to go outside. Having been accustomed to all-dimensional supply of welfare by the units from cradle to grave, people gradually formed a mental state of waiting for and depending on supply from the units. (Zheng, Q., \& Qiao, K., No. 6, 2010) It is thus clear that the residents highly depended on all kinds of supports provided by the government. There is no exception to social organizations in this regard.

Ever since the reform and opening up, decline of the system of units has widened freedom of the popular, which is a good opportunity for people to enhance their autonomy. Quite a large number of people no longer search for "a secure job". Instead, they begin to keep the initiative to choose a work unit, manner of working, location of jobs and location of living, as well as style of life, etc. What's more, the market-oriented economy also offers a platform for free competition, which makes it possible for the popular to fulfill their personal value. At the time when the popular fulfill their personal value, their subjective consciousness is elevated accordingly. Nevertheless, as a matter of fact, disassembly of the system of units, breakthrough of activities by the popular and increase of their subjectivity have not yet brought about springing up of social organizations as expected.

Then, why social organizations fail to boom from bottom to top after collapse of the system of units? Indeed, organization cost incurred by "free-riding" has a relatively common explanatory power. However, this phenomenon simultaneously exists in western countries. Hence, the influential factor that is peculiar to China should be the complex of dependency of the popular upon the nation and administrative organs because of 
administrative control for a long-lasting period. In recent years, the system of community has gradually built up under promotion of the government, and has turned to be the grassroots self-governing organizations in urban cities. Dependency of employees upon the units in the old days, to a large extent, is continuing today in dependency of residents upon a community residents committee. In most cases, a community residents committee functions as a bridge between residents and the government. Therefore, even administrative control of the units retreats from the community residents committee and floating resources are released to the society, people are still more willing to accept arrangement by the community residents committee. As a result, they have no intention to form an association from top to bottom.

To sum up, governmental leading in development of social organizations is actually the outward manifestation of opinion expression habits and deficiency of public spirit. This option has practical rationality through our analysis from both the subjective and objective perspectives in the above text. Compared with experiences in European and American countries, the current situation of China has its own distinct peculiarities. "The traditional way of thinking and cultural background of western countries and the freedom complex of their people have created the opportunity for western society to gain natural differentiation in the old system. This natural differentiation offers directly a structural foundation for its benign integration. Furthermore, this structural foundation supports the institutional framework of the entire western society and enables the entire society to acquire first mover advantages". (Wang, Y., No. 3, 2009) However, in China, the social system which came into being long ago and the complex of great unification as well as the dependency psychology of the popular decide that we shouldn't follow directly the examples of western countries in differentiation of the country and the society.

\section{Theory of Biaxial Relationship}

\subsection{Necessity of Government Effect}

Both theoretical foundation and realistic background lay emphasis on the great significance of government functions on social organizations. This further testifies indispensability of government functions. Establishment and development of social organizations of the government helps to share organizational costs by incentive means of resources. In addition, this helps to offer job opportunities and activity platform, reinforce internal cohesive forces of organizations and expand external influential power. All has had a tremendous promoting effect on formation and development of social organizations. Even the effect on control has also standardized establishment, activities and existence of social organizations by means of laws and regulations. A well-organized activity environment is also indispensable for social organizations.

\subsection{Separation of Control and Support}

It can be understood from the aforementioned analysis that the relationship between support and control is neither waning and waxing, nor "one honors all; one damns all". There is no inevitable connection between the two. Usually, understanding of the relationship between the two is focused on inseparability of the two functions. That is, support is inevitably accompanied by control. This also means social organizations have to exchange part of their autonomy for support from the government, but in reality otherwise. Existence of organizations of rights safeguarding and organizations of service in reality overthrow that viewpoint. The mode of action by the government in organizations of rights safeguarding tells us that it does not mean social organizations may escape from the strict control by the government if they don't accept support from the government. Functions of the government in service organizations indicate that the government will vest a lot of support and free action space for organizations that are encouraged for development. After all, regulatory measures of the government are taken to cope with potential threats or for convenience of supervision, whereas supporting measures are taken to encourage development. The purposes of the two are totally different, let alone any close relationship between them. Evidence on independence of the two kinds of functions, together with our exposition in the preceding text on the necessity of the functions, brings us to put forth a new relationship model --- biaxial relationship model. Tao Chuanjin proposed biaxial relationship theory in his study. Its theoretical connotation is that functions of the nation in the society are dual, including both control and support. (Tao, C., No. 2, 2008) Furthermore, these two functions are mutually independent and have effects on each other.

We have analyzed the behavioral logic of the dual roles of the government. Then, how the dual roles militate on social organizations? Whether they militate simultaneously? On the basis of the biaxial relationship theory, we may further discuss on functions of the government in social organizations. The highlight of this theory lies in the fact that it breaks through the "black box" in the functions of the government and makes distinction between the functions. That is, in addition to control and constraint on the society, the country also gives support and takes a leading role in the society. These two functions together constitute the general function model of the 
government in social organizations, namely, support-control model. On the basis of biaxial relationship theory, this paper will further discuss the manifestation mode of support-control model.

\subsection{Support-Control Model}

Since the two functions of support and control co-exist in the biaxial relationship and also militate independently, not only the two models of "high support -high control" peculiar to the totalitarianism society and "low-support - low control" peculiar to the civil society exist in the relationship between the government and social organizations. Instead, there is theoretical possibility for existence of the other two models of "high support low control" and "low support - high control". Therefrom, with existence of these four types of relationship models, we can continue to establish the support - control" model adopted by the government in social organizations.

\begin{tabular}{cl}
\hline Low support, high control & High support, high control \\
\hline Low support, low control & High support, low control \\
\hline
\end{tabular}

Figure 1. Model of support-control

Compared with uniaxial theory, what biaxial theory covers is more extensive. Hence, the status of government's functions in social organizations manifested in the uniaxial theory can, likewise, be depicted in the biaxial theory. That is, two dimensionalities lie simultaneously in a low or high position, namely, any point on the axis on which the model moves from bottom left to top right. In addition, in the traditional theory, these two statuses describe two extreme conditions. Actually, the relationship of government's functions in social organizations is manifested as more complicated in the same period. The biaxial relationship happens to satisfy this requirement as it is applicable to the governing strategies by the government in different socializations in the same period.

"Low support - low control" is interpreted as mutual independence and no interference between the government and the society in the civil society. However, at the present stage in China, this model means the government puts social organizations in a state of laissez faire. The government neither intervenes in formation of social organizations, nor imposes any constraint on their activities. Of course, the government does not obviously provide any support to social organizations in terms of resources. Basically, it sits back and looks unconcerned about emergence and perishment of social organization. The government adopts the function model of "low support - low control" for entertainment social organizations. A large majority of entertainment social organizations are automatically formed based on the hobbies and interests of citizens. The members of the organizations participate just out of their interest, so they have a sense of natural identify with the organizations. This sense of identity helps to establish the system of membership fees. Thus, the organizations are able to raise funds by themselves and their need of support provided by the government is smaller than other types of social organizations. Furthermore, cultural social organizations focus on the cultural life of residents, so they are unlikely to bring about troubles to social management. What's more, cultural social organizations do not need the government to intervene in their management as their members have high participation enthusiasm. Thus, the government has relatively weak control over such type of social organizations.

"High support - high control" is used to present the period of an omnipotent government in the uniaxial theory. However, in reality, it presents a new situation, which is social organizations release to the government some authorities that are decisive with the aim of acquiring some monopolistic resources. For instance, the government makes decision in selecting primary principals for social organizations, while some significance decisions in social organizations are made by these principles or by governmental sectors. Instead, resources of social organizations mainly originate from the government. Furthermore, with recognition of the government, social organizatioins occupy a monopolistic position in the fields they are involved. The government adopts the function model of "high support - high control" for social organizations in political communities. This type of social organizations is established under the guidance of governmental sectors for realization of certain political purposes. Usually, profound administrative color is shown in terms of institutional setting and behavioral methods. Both personnel salaries and activity expenditures are contained in the financial budget. Compared with other types of social organizations, such support by the government can be said to be extremely generous. With regard to control, the high control of the government on this type of organizations is different from that in the case of rights keeping organizations. The former is out of consideration of convenience for management and supervision, while the latter is out of consideration of precaution. Alike the setting of top-down hierarchical controlling management system and the operational mechanism of all linked with another within the government, 
this type of social organizations is aimed to better execute government policies and fulfill the initial political purpose.

The other two modes in the model reflect conditions in which support and control are asymmetrical. In a realistic society, support of the government on social organizations is not merely confined to delivering resources and social energy to social organizations, but also includes returning the autonomy to social organizations and no longer seeks to take control over them. This is the condition which "high support - low control" corresponds to. Service social organizations integrate social power and resources to provide public services for the public. They are not only able to sensitively perceive the demands of residents within the community, but can also flexibly provide public products and services. Furthermore, this type of social organizations helps to alleviate the working burden of the government and optimize allocation of social resources. For such type of social organizations, the government is, of course, glad to support their existence and will positively push forward their formation and development. In addition, this type of social organizations may not bring about any inconvenience or threat to management of the government. Therefore, the government is not likely to participate in the management of this type of social organizations. Independent operation and relaxed atmosphere encourage production of this type of organizations and is helpful for them to five full play to their functions. Thus, it can be found, a potent helper is not necessarily a potent controller. At the same time, the situation of "low support high control" also exists theoretically. In this mode, the government takes strict control over production and development of social organization, but does not obviously furnish resources. This indicates that the government does not completely negate such a kind of social organizations, but holds a precaution attitude. Among all these four types of models, maybe this model is the most rigorous one for social organizations. However, to a certain extent, this has also proved the fact that support and control are separated.

So far, the issue proposed at the very beginning of the paper has got resolved. That is, the relationship between the nation and social organizations is biaxial, which is specifically manifested as follows. Functions of the government in social organizations are indispensable. The government adopts different composite modes for different social organizations. Our research result has positive theoretical and time significance in study on the relationship between the government and social organizations in China. On one hand, the new theory has been rid of the "vicious cycle in functions of the government" caused by the traditional uniaxial relationship. Social organizations wish to gain support and assistance from the government. However, once the government intervenes, it is easy to give rise to such dangers as reinforced hierarchy and reduced autonomy. On the other hand, establishment of function models helps to clarify governing strategies adopted by the government for different social organizations.

\section{References}

Huang, R. (1992). A Discussion on Chinese History on the Hudson Riverside. Beijing: SDX Joint Publishing Company, p.6.

Kramer, R. (1993). Privatization in four European countries: Comparative studies in government-third sector relationships. Armonk NY: M.E. Sharpe.

Kuhnle, S., \& Selle P. (1992). Government and voluntary organizations: a relational perspective. Aldershot, Hants, England; Brookfield, Vt: Ashgate.

Saidel J. (1991). Resource Interdependence: The Relationship between State Agencies and Nonprofit Organizations. Public Administration Review, 51(6). https://doi.org/10.2307/976605

Tao, C. (2008). Control and Support: Study on the Two Independent Relationships between a Nation and the Society - A Situation in Chinese Rural Society. Management World, (2).

Wang, Y. (2009). An Analysis of Restrictive Conditions for Development of Non-Governmental Organizations in China. Jianghai Academic Journal, (3).

Zheng, Q., \& Qiao, K. (2010). On Government Cultivation Oriented Path Generated by Community. Social Science of Beijing, (6).

\section{Copyrights}

Copyright for this article is retained by the author(s), with first publication rights granted to the journal.

This is an open-access article distributed under the terms and conditions of the Creative Commons Attribution license (http://creativecommons.org/licenses/by/4.0/). 